\title{
IL-28B single nucleotide polymorphism as a predictor of hepatocellular carcinoma after treatment of chronic hepatitis C patients with direct acting antivirals
}

\author{
Nancy Abdel Fattah Ahmed ${ }^{1 *}$, Ahmed Shawky Hassan Ali², Rizk Ahmed El Baz $z^{3}$ and \\ Islam Abd El-Hamid El-Zayyadi²
}

\begin{abstract}
Background: Hepatitis C virus (HCV) infection is considered one of the main causes of chronic liver diseases. HCV is responsible for $25 \%$ of HCC cases worldwide. DAAs represent an important step for HCV eradication. The aim was to study the role of IL-28B single nucleotide polymorphism in the prediction of HCC in patients with HCV-related cirrhosis after DAAs.

Results: This study was done at Mansoura Specialized Hospital: 50 cases HCC after DAAs, 50 cases without HCC after DAAs, and 100 controls. SNPs of the IL-28B gene were genotyped. There was an insignificant difference between HCC patients and the cirrhotic group as regards genotypes ( $p$ value $=0.26$ ) and alleles $(p$ value $=0.77)$. A significant association in SNP of IL-28B between healthy individuals and the cirrhotic group was detected. C C genotype (28\%) and C T (64\%) genotype were more prevalent in the healthy group than in the cirrhotic group 20\% and 52\% respectively while T T genotype was more prevalent in cirrhotic patients (28\%) than controls (8\%). C allele was protective against cirrhosis with $60 \%$ distribution in healthy individuals and $46 \%$ in the cirrhotic group. T allele was more prevalent in cirrhotic (54\%) than the normal group (40\%)
\end{abstract}

Conclusion: Although IL-28B SNP had a role in HCV-related cirrhosis progression, it did not predict the probability for HCC development following DAAs.

Keywords: HCV, HCC, SNPs

\section{Background}

Hepatitis $\mathrm{C}$ virus $(\mathrm{HCV})$ infection is considered one of the main causes of chronic liver diseases around the world. There are about 71 million chronically infected persons [1]. $\mathrm{HCV}$ is responsible for $27 \%$ of cases of cirrhosis and $25 \%$ of HCC cases worldwide [2]. Hepatocellular carcinoma (HCC) is the primary liver cancer derived from the hepatocytes [3]. DAAs represent uprising

\footnotetext{
* Correspondence: ziad.emad90@yahoo.com

'Mansoura Specialized Medical Hospital, Internal Medicine Department Hepatology \& Gastroenterology Unit, Faculty of Medicine, Mansoura University, Mansoura, Egypt

Full list of author information is available at the end of the article
}

in $\mathrm{HCV}$ eradication [4]. The incidence of $\mathrm{HCC}$ is reduced in chronic hepatitis $\mathrm{C}$ genotype 4 patients with liver cirrhosis (F4) and advanced hepatic fibrosis (F3) who achieved SVR following DAAs treatment to $2.9 \%$ as compared with $5.3 \%$ in untreated patients [5]. Especially in absence of HCC risk factors, the recurrence incidence is decreased [6], also most recent articles found a reduced incidence, and the debate is near the end [7]. Unexpected high rate of HCC recurrence has been reported about $28.8 \%$ despite complete response to treatment [8]. IL-28B is a cytokine responsible for transcription of subsets of genes that play a crucial role in antiviral immune response [9]. Although the role of IL-

\section{Springer Open}

() The Author(s). 2021 Open Access This article is licensed under a Creative Commons Attribution 4.0 International License, which permits use, sharing, adaptation, distribution and reproduction in any medium or format, as long as you give appropriate credit to the original author(s) and the source, provide a link to the Creative Commons licence, and indicate if changes were made. The images or other third party material in this article are included in the article's Creative Commons licence, unless indicated otherwise in a credit line to the material. If material is not included in the article's Creative Commons licence and your intended use is not permitted by statutory regulation or exceeds the permitted use, you will need to obtain permission directly from the copyright holder. To view a copy of this licence, visit http://creativecommons.org/licenses/by/4.0/. 
28B SNP in HCC remains controversial, single nucleotide polymorphism of IL-28B can predict the response to DAAs with favorable and unfavorable genotypes [10].

\section{Objectives}

The objective is to study the role of IL-28B single nucleotide polymorphism in the prediction of HCC in patients with HCV-related cirrhosis after DAAs.

\section{Methods}

Study design

The present study was a cross-sectional study.

\section{Settings}

The study was conducted at Mansoura Specialized Medical Hospital.

\section{Participants}

This study included 50 cirrhotic patients due to HCV with a history of DAA therapy, 50 cirrhotic patients due to $\mathrm{HCV}$ with history of DAA therapy who developed HCC, 100 normal individuals neither infected by HCV nor had HCC as a control group, and all of them were from Mansoura Specialized Medical Hospital.

\section{Variables}

\section{Inclusion criteria}

Inclusion criteria include adult patients $18-65$ years at Specialized Medical Hospital, Mansoura University inpatient and outpatient departments. They received DAAs therapy (sofosbuvir $400 \mathrm{mg}$ once daily, daclatasvir $60 \mathrm{mg}$ once daily, ribavirin $800-1200 \mathrm{mg}$ ) and SVR after 3 months of therapy or after 6 months of sofosbuvir and daclatasvir in patients who did not tolerate ribavirin.

\section{Exclusion criteria}

1. Co-infection with HBV or HIV.

2. Previous $\mathrm{HCV}$ treatment with interferon-based therapy.

3. Other etiologies of cirrhosis: autoimmune hepatitis, $\mathrm{NASH}$, alcoholic, and other causes.

4. Known drug abuse.

5. Pregnant females.

6. Organ failure: heart failure, respiratory failure, renal failure.

\section{Data sources/measurement}

All selected patients were subjected to history taking and physical examination.

\section{Laboratory and radiological investigations}

These include complete blood count (CBC), serum albumin, total, direct bilirubin, INR, AST, ALT, creatinine, alpha fetoprotein, and IL28B gene polymorphism PCR.

Also, abdominal ultrasound, triphasic CT: HCC cases were diagnosed based on the arterial phase enhancement and washout during the portal venous phase. One case underwent liver biopsy after CT and MRI had been done without definite diagnosis of HCC and revealed undifferentiated carcinoma.

Bias

N/A

\section{Study size}

The study size is determined by the statistician.

\section{Quantitative variables}

N/A

\section{Statistical methods}

The collected data were coded and fed into the SPSS system (Statistical Package for Social Sciences) ver. 22

\section{Results}

Table 1 shows that groups are matched according to age and sex with male predominance in both cirrhotic and $\mathrm{HCC}(p$ value $=0.135, p$ value $=0.06)$, respectively

Table 2 shows significant increase in hepatic decompensation in the HCC group as regards encephalopathy, ascites, jaundice, and hematemesis ( $p$ value $=0.008, p$ value $=0.04, p$ value $=0.001$, and $p$ value $=0.023$, respectively)

Table 3 shows significant lower serum albumin, Hgb, and platelets in HCC group with $p$ value $=0.02, p$ value $=0.03$, and $p<0.001$, respectively, and a significant higher AST, total, direct bilirubin, and INR in the HCC group with $p$ value $=0.001, p=0.005, p=0.02$, and $p=$ 0.009 , respectively.

Table 4 shows a significant increase in Child B and C among the HCC group ( $p$ value $<0.001$ )

Table 5 shows the classification of HCC according to the number of lesions and BCLC, duration between end of treatment and HCC and associated PVT, and nodal and extrahepatic spread.

$p 1$ difference between the control group and cirrhotic group, $p 2$ difference between the control group and HCC, $p 3$ difference between the cirrhotic and HCC cases

Table 6 shows an insignificant distribution in genotypes and alleles of IL-28B SNP between the HCC group and cirrhotic group and a significant distribution in genotypes and alleles between the control and cirrhotic groups. 
Table 1 Demographic characteristics of the studied groups

\begin{tabular}{lllll}
\hline & $\begin{array}{l}\text { Control group } \\
\boldsymbol{N}=\mathbf{1 0 0}\end{array}$ & $\begin{array}{l}\text { Cirrhosis group } \\
\boldsymbol{N}=\mathbf{5 0}\end{array}$ & $\begin{array}{l}\text { HCC group } \\
\boldsymbol{N = 5 0}\end{array}$ & Test of significance \\
\hline $\begin{array}{llll}\text { Age/years } \\
\text { Mean } \pm \text { SD }\end{array}$ & & & $57.08 \pm 6.74$ & $t=1.51$ \\
Sex, $n(\%)$ & $57.92 \pm 7.40$ & $55.24 \pm 5.42$ & & $p=0.135$ \\
Male & & & $37(74.0)$ & $X^{2}=5.70$ \\
Female & $58(58.0)$ & $33(66.0)$ & $13(26.0)$ & $p=0.06$ \\
\hline
\end{tabular}

*Statistically significant (if $p<0.05$ )

Table 7 shows that age and AFP are significant ( $p$ value $=0.002, p$ value $=0.009)$ respectively as predictors of $\mathrm{HCC}$.

Table 8 shows a significant association between genotype and PVTT $(P$ value $=0.02)$ and an insignificant association between genotype and other criteria of $\mathrm{HCC}$ cases

\section{Participants}

This study included 50 cirrhotic patients due to HCV with a history of DAA therapy, 50 cirrhotic patients due to $\mathrm{HCV}$ with a history of DAA therapy who developed HCC, and 100 normal individuals neither infected by HCV nor had HCC as a control group.

\section{Descriptive data, outcome data, and main results}

Descriptive data, outcome data, and main results are shown in Tables $1,2,3,4,5,6,7$, and 8 .

\section{Other analyses}

$\mathrm{N} / \mathrm{A}$

\section{Key results}

IL-28B SNP could not predict HCC development after DAAs.

IL-28 SNP had a significant role in the development of $\mathrm{HCV}$-related cirrhosis.

AFP and age are strong predictors of HCC.

HCC leads to rapid deterioration of liver functions.
Close follow-up by US and AFP is recommended post DAAs specially in advanced fibrosis and cirrhosis.

\section{Discussion}

This work has great importance as prediction of post DAAS HCC is the headache association of such revolution in the treatment of HCV-related liver disease, reaffirming the role of IL-28B SNP in progression to and of cirrhosis is expected, and the results were surprising.

The present study includes $50 \mathrm{HCC}$ patients post DAAs, 50 cirrhotic patients post DAAs without HCC, and 100 normal as a control.

In our study, the distribution of the polymorphisms between the HCC group and cirrhotic group was close in both, and no significant differences were found. In the HCC group, $\mathrm{C} C$ genotype, $\mathrm{T} \mathrm{T}$ genotype, and $\mathrm{C} \mathrm{T}$ genotype were $14 \%, 18 \%$, and $68 \%$ while they represented $20 \%, 28 \%$, and $52 \%$ respectively in cirrhotic group ( $p$ value $=0.26$ ). As regards alleles, there were no significant differences for $\mathrm{C}$ and $\mathrm{T}$ alleles between the HCC group $(48 \%, 52 \%)$ and cirrhotic group $(46 \%, 54 \%)(p$ value $=0.77$ ).

These results denote a lack of association between SNP of IL-28B and HCC post DAAs. Therefore, SNP of IL-28B cannot predict the emergence of HCC after DAAs.

Salum et al. [11] reported similar results of no significance was found in SNP of IL-28B in prediction of HCC post DAAs. They found $\mathrm{C} \mathrm{C}, \mathrm{T} \mathrm{T}$, and $\mathrm{C} \mathrm{T}$ genotypes

Table 2 clinical presentation of the studied groups

\begin{tabular}{|c|c|c|c|}
\hline & $\begin{array}{l}\text { Cirrhosis group } \\
N=50(\%)\end{array}$ & $\begin{array}{l}\text { HCC group } \\
N=50(\%)\end{array}$ & Test of significance \\
\hline Hepatic encephalopathy & $8(16.0)$ & $20(40.0)$ & $\begin{array}{l}x^{2}=7.14 \\
p=0.008^{*}\end{array}$ \\
\hline Ascites & $17(34.0)$ & $27(54.0)$ & $\begin{array}{l}x^{2}=4.06 \\
p=0.04^{*}\end{array}$ \\
\hline Jaundice & $11(22.0)$ & $26(52.0)$ & $\begin{array}{l}x^{2}=9.65 \\
p=0.001^{*}\end{array}$ \\
\hline Hematemesis & $26(52.0)$ & $37(74.0)$ & $\begin{array}{l}x^{2}=5.19 \\
p=0.023^{*}\end{array}$ \\
\hline DM & $20(40.0)$ & $18(36.0)$ & $\begin{array}{l}x^{2}=0.170 \\
p=0.680\end{array}$ \\
\hline
\end{tabular}


Table 3 Laboratory results of the studied groups

\begin{tabular}{|c|c|c|c|}
\hline & $\begin{array}{l}\text { Cirrhosis group } \\
N=50\end{array}$ & $\begin{array}{l}\text { HCC group } \\
N=50\end{array}$ & Test of significance \\
\hline INR & $1.49 \pm 0.37$ & $1.29 \pm 0.34$ & $\begin{array}{l}t=2.68 \\
p=0.009^{*}\end{array}$ \\
\hline Albumin (g/dl) & $3.12 \pm 0.49$ & $2.83 \pm 0.77$ & $\begin{array}{l}t=2.29 \\
p=0.024^{*}\end{array}$ \\
\hline AST (IU/ml) & $55.70 \pm 37.29$ & $95.0 \pm 73.97$ & $\begin{array}{l}z=3.21 \\
p=0.001^{*}\end{array}$ \\
\hline ALT (IU/ml) & $46.50 \pm 24.52$ & $60.22 \pm 41.63$ & $\begin{array}{l}z=1.44 \\
p=0.149\end{array}$ \\
\hline Platelet/cm $\left(\times 10^{3}\right)$ & $106.22 \pm 42.06$ & $88.02 \pm 39.54$ & $\begin{array}{l}z=2.23 \\
p=0.001^{*}\end{array}$ \\
\hline $\mathrm{WBCs} / \mathrm{cm}$ & $5.74 \pm 2.61$ & $6.44 \pm 2.96$ & $\begin{array}{l}z=1.18 \\
p=0.235\end{array}$ \\
\hline $\mathrm{Hgb}(\mathrm{g} / \mathrm{dl})$ & $9.11 \pm 0.97$ & $9.71 \pm 1.73$ & $\begin{array}{l}t=2.12 \\
p=0.036^{*}\end{array}$ \\
\hline Creatinine (mg/dl) & $1.11 \pm 0.37$ & $1.18 \pm 0.49$ & $\begin{array}{l}t=0.851 \\
p=0.397\end{array}$ \\
\hline Total bilirubin (mg/dl) & $2.76 \pm 2.7$ & $5.09 \pm 5.27$ & $\begin{array}{l}z=2.82 \\
p=0.005^{*}\end{array}$ \\
\hline Direct bilirubin (mg/dl) & $1.67 \pm 2.06$ & $3.15 \pm 3.6$ & $\begin{array}{l}z=2.19 \\
p=0.028^{*}\end{array}$ \\
\hline
\end{tabular}

*Statistically significant (if $p<0.05$ )

were $31 \%, 6 \%$, and $55 \%$ in HCC group while in cirrhotic group were $27 \%, 20 \%$, and $26 \%$ ( $p$ value $=0.457$ ). For alleles, they found in the HCC group C allele was $58 \%$ and $\mathrm{T}$ allele was $42 \%$, while in the cirrhotic group, $\mathrm{C}$ allele was $53 \%$ and $\mathrm{T}$ alleles was $47 \%$ ( $p$ value $=0.31$ ) which also refer to lack of significance between SNP of IL-28 and HCC post DAAs.

On the opposite side, Simili et al. [12] reported a significant association between SNP of IL-28 and HCC post DAAs. $\mathrm{T} T$ genotype was unfavorable and associated with a higher risk of HCC post DAAs ( $p$ value $=0.024$ ).

This conflict with the previous results is found as this study included a small number of HCC cases after DAAs of only 11 patients. Six of them had a history of HCC and were treated at least 6 months before DAAs, and 5 of them were without recurrence while a number of patients without recurrence in our study was 50 cases and in Salum et al. [11] was 65 patients.

Table 4 Child-Pugh score classification distribution among studied groups

\begin{tabular}{llll}
\hline & $\begin{array}{l}\text { Cirrhosis group } \\
\boldsymbol{N = 5 0 ( \% )}\end{array}$ & $\begin{array}{l}\text { HCC group } \\
\boldsymbol{N = 5 0 ( \% )}\end{array}$ & Test of significance \\
\hline Child score & & & \\
A & $34(68.0)$ & $6(12.0)$ & $X^{2}=33.21$ \\
B & $13(26.0)$ & $31(62.0)$ & $P<0.001^{*}$ \\
C & $3(6.0)$ & $13(26.0)$ & \\
\hline
\end{tabular}

*Statistically significant (if $p<0.05$ )
HCV Genotype 4 is the most common genotype in Egypt while genotype 1a is the most common in Europe. Genotype distribution is important in predicting disease progression, response to therapy, progression of fibrosis, and a higher risk of HCC [13].

In our study, a significant association between SNP of IL-28B in healthy individuals and the cirrhotic group was detected $(p$ value $=0.004)$. A significant increase was observed in frequencies of IL-28B C C genotype in the healthy population (28\%) than the cirrhotic group (20\%) and in $\mathrm{C} \mathrm{T}(64 \%)$ genotype in the healthy group than

Table 5 Characterization of HCC cases

\begin{tabular}{ll}
\hline Character & $\begin{array}{l}\text { HCC group } \\
(\boldsymbol{N = 5 0 )}\end{array}$ \\
\hline PVT & $11(22 \%)$ \\
Extrahepatic, LN spread & $7(14 \%)$ \\
Median period between EOT and HCC & $18 \mathrm{~m} \pm 6 \mathrm{~m}$ \\
Number of focal lesions & \\
$\quad$ Single & $23(46 \%)$ \\
$2-3$ & $12(24 \%)$ \\
$>3$ & $15(30 \%)$ \\
BCLC & \\
Very early, early $(0, A)$ & $12(24 \%)$ \\
Intermediate (B) & $16(32 \%)$ \\
Advanced (C) & $4(8 \%)$ \\
Terminal (D) & $18(36 \%)$ \\
\hline
\end{tabular}


Table 6 Genotypes and alleles distribution among studied groups

\begin{tabular}{|c|c|c|c|c|c|}
\hline Polymorphism & $\begin{array}{l}\text { Control group } \\
N=100(\%)\end{array}$ & $\begin{array}{l}\text { Cirrhosis group } \\
N=50(\%)\end{array}$ & $\begin{array}{l}\text { HCC group } \\
N=50(\%)\end{array}$ & Test of significance & \\
\hline Tा & $8(8.0)$ & $14(28.0)$ & $9(18.0)$ & $x^{2}=13.12$ & $\mathrm{p} 1=0.004^{*}$ \\
\hline CC & $28(28.0)$ & $10(20.0)$ & $7(14.0)$ & $p=0.01^{*}$ & $\mathrm{p} 2=0.054$ \\
\hline$C T$ & $64(64.0)$ & $26(52.0)$ & $34(68.0)$ & & $p 3=0.26$ \\
\hline HWE & $0.008^{*}$ & 0.741 & 0.126 & & \\
\hline Allele & $n=200$ & $N=100$ & $N=100$ & & $\mathrm{p} 1=0.02^{*}$ \\
\hline $\mathrm{T}$ & $80(40)$ & $54(54.0)$ & $52(52.0)$ & $x^{2}=6.87$ & $\mathrm{p} 2=0.051$ \\
\hline C & $120(60)$ & $46(46.0)$ & $48(48.0)$ & $p=0.03^{*}$ & $\mathrm{p} 3=0.77$ \\
\hline
\end{tabular}

*Statistically significant (if $p<0.05$ )

the cirrhotic group (52\%). On the other hand, $\mathrm{T} T$ genotype was more prevalent in cirrhotic patients $(28 \%)$ than controls $(8 \%)$.

As regards alleles, $\mathrm{C}$ allele appeared to be protective against cirrhosis with $60 \%$ distribution in healthy individuals and $46 \%$ in the cirrhotic group. $\mathrm{T}$ allele was more prevalent in cirrhotic (54\%) than the normal group $(40 \%)(p$ value $=0.02)$

A significant increase $(P<0.0005)$ was observed in frequencies of IL-28B C C genotypes in the healthy population than in the cirrhotic group (48\%, 13\%) respectively [14].

Attallah et al. [15] found that IL-28B T T genotype is more prevalent in patients with advanced fibrosis and cirrhosis among HCV genotype 4 Egyptian patients ( $p$ value $\left.{ }^{<} 0.05\right)$.

Also, Fuente et al. [16] found TT genotype in IL28B polymorphism was highly prevalent in HCV cirrhotic patients but it did not directly influence hepatocarcinogenesis.

These similar results suggest the role of SNP IL-28 in $\mathrm{HCV}$ disease progression and liver cirrhosis.

\section{Limitations}

Transient elastography was not done as it is very expensive for our patients. Also, the relatively small number of patients was due to the difficulty in acceptance by patients to be included in a research study in addition to the high expense of the kits.

Table 7 Predictors of hepatocellular carcinoma among studied cases

\begin{tabular}{llll}
\hline & $\boldsymbol{\beta}$ & $\boldsymbol{P}$ value & AOR $(\mathbf{9 5} \% \mathrm{Cl})$ \\
\hline Age/years & 0.167 & 0.002 & $1.182(1.06-1.32)$ \\
Albumin $(\mathrm{g} / \mathrm{dl})$ & -0.542 & 0.363 & $0.582(0.181-1.87)$ \\
AST $(\mathrm{IU} / \mathrm{ml})$ & 0.006 & 0.370 & $1.006(0.993-1.02)$ \\
AFP $(\mathrm{ng} / \mathrm{ml})$ & 0.181 & 0.009 & $1.198(1.05-1.37)$ \\
$\mathrm{Hb}(\mathrm{g} / \mathrm{dl})$ & 0.295 & 0.393 & $1.343(0.683-2.64)$ \\
Total bilirubin $(\mathrm{mg} / \mathrm{dl})$ & -1.093 & 0.314 & $0.335(0.04-2.82)$ \\
Direct bilirubin $(\mathrm{mg} / \mathrm{dl})$ & 1.337 & 0.349 & $3.809(0.233-62.38)$ \\
\hline
\end{tabular}

*Statistically significant (if $p<0.05$ )

\section{Interpretation}

Our results should be interpreted with caution because of several limitations. We recruited 200 samples in this study; the sample size of each group was relatively small which may restrict its detailed subgroup analysis by the clinical index. All participants were all from Mansoura Specialized Medical Hospital which may not stand for all the Egyptian population.

\section{Generalizability}

The fundamental experiments should be further conducted to validate our results and explore the possible mechanism.

Table 8 Association between genotype and demographic and laboratory findings among studied HCC cases

\begin{tabular}{|c|c|c|c|c|}
\hline & $\begin{array}{l}\mathrm{CC} \\
N=7\end{array}$ & $\begin{array}{l}T \\
N=9\end{array}$ & $\begin{array}{l}C T \\
N=34\end{array}$ & Test of significance \\
\hline DM & 3 & 6 & 9 & $P=0.245$ \\
\hline \multicolumn{5}{|l|}{ Sex } \\
\hline Male & 5 & 10 & 22 & $P=0.73$ \\
\hline Female & 2 & 2 & 9 & \\
\hline \multicolumn{5}{|l|}{ AF } \\
\hline$>400$ & 4 & 2 & 14 & $P=0.356$ \\
\hline$\leq 400$ & 3 & 7 & 20 & \\
\hline PVT & 2 & 3 & 6 & $P=0.02^{*}$ \\
\hline Child & & & & $P=0.162$ \\
\hline A & 3 & 2 & 10 & \\
\hline B & 2 & 2 & 17 & \\
\hline C & 2 & 5 & 7 & \\
\hline Size & & & & $P=0.144$ \\
\hline$\leq 5$ & 5 & 3 & 23 & \\
\hline$>5$ & 2 & 6 & 11 & \\
\hline \multicolumn{5}{|c|}{ Number of lesions } \\
\hline Single & 4 & 2 & 10 & $P=0.468$ \\
\hline$\leq 3$ & 2 & 3 & 15 & \\
\hline$>3$ & 1 & 4 & 9 & \\
\hline
\end{tabular}




\section{Conclusion}

Although IL-28B SNP had a role in HCV-related cirrhosis progression, it did not predict the probability for HCC development following DAAs. Further studies are recommended.

\begin{abstract}
Abbreviations
HCV: Hepatitis C virus; HCC: Hepatocellular carcinoma; SNPs: Single nucleotide polymorphisms; AFP: Alpha fetoprotein; DAAs: Direct-acting antivirals; SVR: Sustained virologic response; HIV: Human immunodeficiency virus; HBV: Hepatitis B virus; PCR: Polymerase chain reaction; ALT: Alanine aminotransferase; AST: Aspartate transaminase; INR: International normalized ratio; CBC: Complete blood count; SPSS: Statistical Package for the Social Sciences; AUC: Area under the curve; CT: Computed tomography; AOR: Adjusted odds ratio; HWE: Hardy-Weinberg Equilibrium; JAK: Janus kinase; STAT: Signal transducer and activator of transcription proteins
\end{abstract}

\section{Acknowledgements}

Thanks to every person shared in this work and the National Committee for control of viral hepatitis for their great efforts.

\section{Study design}

The present study was cross-sectional in nature, and patients were selected from Mansoura Specialized Medical Hospital, Faculty of Medicine, Mansoura University.

\section{Authors' contributions}

The authors have read and approved the manuscript. NAFA (CA): idea of the study, design, and publishing. ASHA: literature search, clinical follow-up, and statistics. RAEB: laboratory studies. IAEE: manuscript review, editing, and data collection

\section{Funding}

Not applicable.

\section{Availability of data and materials}

The datasets used and/or analyzed during the current study are available from the corresponding author on reasonable request.

\section{Declarations}

\section{Ethics approval and consent to participate:}

The study protocol was investigated and approved by the Medical Ethics Research Team, Faculty of Medicine, Mansoura University (code number MS. 18. 11.364). Every case, after guaranteeing privacy, has given informed written consent

\section{Consent for publication}

Not applicable.

\section{Competing interests}

The authors declare that they have no competing interests.

\section{Author details}

${ }^{1}$ Mansoura Specialized Medical Hospital, Internal Medicine Department Hepatology \& Gastroenterology Unit, Faculty of Medicine, Mansoura University, Mansoura, Egypt. ${ }^{2}$ Specialized Medical Hospital,Internal Medicine Department, Faculty of Medicine, Mansoura University, Mansoura, Egypt. ${ }^{3}$ Genetic Unit, Pediatric Hospital, Faculty of Medicine, Mansoura University, Mansoura, Egypt.

Received: 20 January 2021 Accepted: 28 April 2021

Published online: 07 May 2021

\section{References}

1. Ahmed NAF, Deiab AG, Hasan ASM, Abd Elbaky AMY (2020) Serum autotaxin levels in responders to HCV treatment by direct-acting antivirals. Egypt Liver J 10(1):1-4

2. Vescovo T, Refolo G, Vitagliano G, Fimia GM, Piacentini M (2016) Molecular mechanisms of hepatitis C virus-induced hepatocellular carcinoma. Clinical
Microbiology and Infection 22(10):853-861. https://doi.org/10.1016/j.cmi.201 6.07.019

3. Ozakyol A (2017) Global epidemiology of hepatocellular carcinoma (HCC epidemiology). Journal of gastrointestinal cancer 48(3):238-240. https://doi. org/10.1007/s12029-017-9959-0

4. Schinazi R, Halfon P, Marcellin P, Asselah T (2014) HCV direct-acting antiviral agents: the best interferon-free combinations. Liver International 34:69-78. https://doi.org/10.1111/liv.12423

5. Shiha, G., Mousa, N., Soliman, R., NNH Mikhail, N., Adel Elbasiony, M. and Khattab, M., 2020. Incidence of HCC in chronic hepatitis C patients with advanced hepatic fibrosis who achieved SVR following DAAs: a prospective study. J Viral Hepatitis, 27, 7, 671, 679, DOI: https://doi.org/10.1111/jvh.13276

6. Guarino M, Di Costanzo GG, Bruzzese D, Sessa A, etal (2020) Incidence of $\mathrm{HCC}$ recurrence after DAA treatment for HCV in a multicentre Italian cohort study. Liver Cancer Int 1(1):12-24. https://doi.org/10.1002/lci2.13

7. Muzica CM, Stanciu C, Huiban L, Singeap AM, Sfarti C, Zenovia S, Cojocariu C, Trifan A (2020) Hepatocellular carcinoma after direct-acting antiviral hepatitis C virus therapy: a debate near the end. World J Gastroenterol 26(43):6770

8. Conti F, Buonfiglioli F, Scuteri A, Crespi C, Bolondi L, Caraceni P, Foschi FG, Lenzi M, Mazzella G, Verucchi G, Andreone P (2016) Early occurrence and recurrence of hepatocellular carcinoma in HCV-related cirrhosis treated with direct-acting antivirals. J Hepatol 65(4):727-733. https://doi.org/10.1016/j. jhep.2016.06.015

9. Zhang Y, Zhu SL, Chen J, Li LQ (2016) Meta-analysis of associations of interleukin-28B polymorphisms rs8099917 and rs12979860 with development of hepatitis virus-related hepatocellular carcinoma. OncoTargets Ther 9:3249

10. Bazeed MMM, Elsheety AG, Bakeer MS, Saber MA, Mohammady EAN (2018) Comparison between clinical and biochemical versus interleukin $28 \mathrm{~B}$ as a predictive factor of virological response to direct antiviral drugs without interferone in treatment of hepatitis C virus patients. Egypt J Hosp Med 73(10):7842-9.

11. Salum GM, Dawood RM, Abd el-Meguid, M., Ibrahim, N.E., Aziz, A.O.A. and El Awady, M.K. (2020) Correlation between IL28B/TLR4 genetic variants and HCC development with/without DAAs treatment in chronic HCV patients. Genes Dis 7(3):392-400. https://doi.org/10.1016/j.gendis.2019.05.004

12. Simili A, Mazzella G, Ravaioli F, Festi D, Bacchi-Reggiani ML, Porro A, Bazzoli F. Azzaroli F (2019) Interleukin 28 polymorphisms and hepatocellular carcinoma development after direct acting antiviral therapy for chronic hepatitis C. J Gastrointestinal Liver Dis 28(4):449-456. https://doi.org/10.154 03/jgld-309

13. Goel A, Ahmed A, Waked I (2019) Clinical epidemiology of hepatitis C virus. In: Clinical Epidemiology of Chronic Liver Diseases. Springer, Cham, pp 149-170

14. El-Awady MK, Mostafa L, Tabll AA, Abdelhafez TH, El Din NGB, Zayed N, El Shenawy R, El Abd Y, Hasan RM, Zaghlol H, El Khayat H (2012) Association of IL28B SNP with progression of Egyptian HCV genotype 4 patients to end stage liver disease. Hepatitis Monthly 12(4):271

15. Attallah AM, Omran D, Marie MS, Abdelrazek M, Salama A, El Essawey R, Mobarak L, Maklad S, Omar A (2018) IL-28B rs12979860 polymorphism affect the course of chronic hepatitis and the development of HCC in Egyptian patients with hepatitis C type 4. British Journal of Biomedical Science 75(4): 157-162. https://doi.org/10.1080/09674845.2018.1489599

16. Fuente S, Citores MJ, Duca A, Cisneros E, Baños I, Vilches C, Cuervas-Mons V (2017) Interleukin-28B TT genotype is frequently found in patients with hepatitis $C$ virus cirrhosis but does not influence hepatocarcinogenesis. Clin Exp Med 17(2):217-223. https://doi.org/10.1007/s10238-016-0418-1

\section{Publisher's Note}

Springer Nature remains neutral with regard to jurisdictional claims in published maps and institutional affiliations. 